\title{
Fabrication and Research of a Novel NLO Material: Tristhiourea Lanthanum Bromide
}

\author{
V. S. Kumar ${ }^{1}$, R. S. Sundararajan ${ }^{2}$ \\ ${ }^{1}$ Department of Physics, Swami Dayananda College of Arts and Science, Manjakkudi, Tiruvarur Dt., Tamilnadu, \\ India \\ ${ }^{2}$ Department of Physics, Government Arts College (Autonomous), Kumbakonam, Tamilnadu, India \\ Email: shanmugavsk.2010@gmail.com
}

Received 9 March 2015; accepted 13 May 2015; published 15 May 2015

Copyright (C) 2015 by authors and Scientific Research Publishing Inc.

This work is licensed under the Creative Commons Attribution International License (CC BY).

http://creativecommons.org/licenses/by/4.0/

(c) (i) Open Access

\begin{abstract}
The single crystals of tristhiourea lanthanum bromide (TTLaB) have been grown by solution growth using slow evaporation technique. The grown crystals were characterized by single crystal X-ray diffraction (XRD) to study the crystal structure. The presence of functional groups was identified through Fourier transform-infrared technique. The optical study exposed that the crystal has high transmission with lower cut off wavelength of $237.43 \mathrm{~nm}$. The Elemental analysis confirmed atoms present in the grown compound. The NLO (Non Linear Optical) behavior of TTLaB crystal was tested by Kurtz-Perry powder technique. This novel semi-organic single crystal of TTLaB exhibited very good optical transmission property, high mechanical strength and large non-linearity nature.
\end{abstract}

\section{Keywords}

Nonlinear Optical, Tristhiourea Lanthanum Bromide, Second Harmonic Generation, Fourier Transform Infrared spectrum

\section{Highlights}

- TTLaB crystals were grown by slow evaporation method.

- These crystals exhibited a good optical property.

- TTLaB crystals have high physical strength.

\section{Introduction}

In crystal growth research, for the past four decades, activities have been focused towards the NLO (Non Linear

"Corresponding author. 
Optical) crystals by researchers. In recent times, number of semi-organic crystals have been walk around, owing to their optoelectronic technologies, good mechanical strength, nonlinearity nature [1]-[4]. In recent research, semi-organic crystals with large nonlinear susceptibility, good optical transparency with high hardness have been identified. Semi-organic complex of thiourea (TU) with good optical nonlinearity combined with the physical austerity of inorganic compound have been useful for device applications. In the present work, we report a new semi-organic NLO material, tristhiourea lanthanum bromide (TTLaB) which has proficient optical second harmonic generation. The title compound crystal thus has high resourceful optical quality for wide applications in the field of laser communication, laser technology and data storage tools [5].

\section{Experimental}

The crystals of Tristhiourea lanthanum bromide were grown by dissolving thiourea and lanthanum bromide in deionized water in the molar ratio of 3:1. The following reaction estimates the needed amount of thiourea and lanthanum bromide.

$$
3 \mathrm{CS}\left[\mathrm{NH}_{2}\right]_{2}+\mathrm{LaBr}_{3} \rightarrow \mathrm{La}\left[\mathrm{CS}\left(\mathrm{NH}_{2}\right)_{2}\right]_{3} \mathrm{Br}_{3}
$$

The solution was stirred using magnetic stirrer. The mixture was heated up to $50^{\circ} \mathrm{C}$ and kept for slow evaporation at room temperature. The spurious growth was trounced by using constant temperature bath at a constant temperature. The temperature of water in the tank was controlled digitally by using microprocessor. Variation in temperature of the bath can be tuned to an accuracy of $\pm 0.1^{\circ} \mathrm{C}$. Optically high quality crystals of TTLaB were harvested in span of 40 days. The photograph of TTLaB crystals were grown by solution growth using slow evaporation method is shown in Figure 1.

\section{Characterization}

A grown TTLaB crystal was subjected to single crystal XRD method to estimate the lattice parameters and crystal structure by using ENRAF NONIUS CAD4 X-ray diffractometer. The grown crystals of TTLaB were focused to Fourier transform infrared spectrum analysis by $\mathrm{KBr}$ pellet technique using a Bruker 66V FTIR spectrometer for the confirmation of vibrational structure analysis with the scanning range of wave numbers 400 $4000 \mathrm{~cm}^{-1}$. The optical transmittance spectra were recorded using VARIAN CARY 5E spectrometer in the range

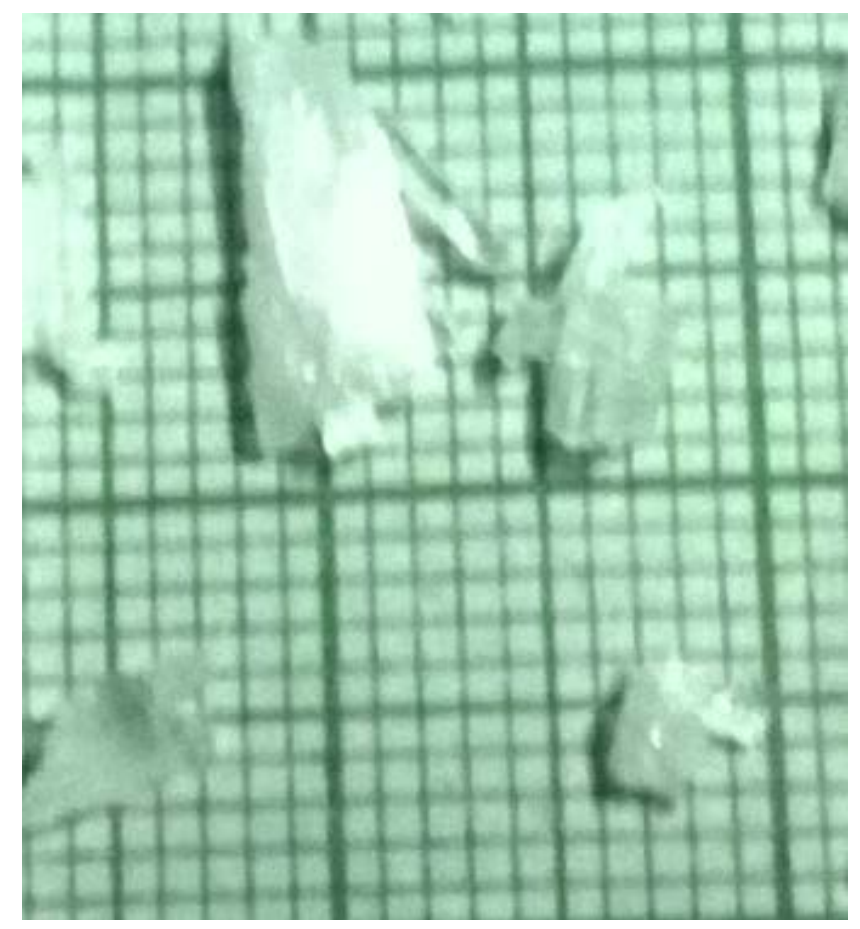

Figure 1. Photograph of the grown TTLaB crystals. 
of 200 - $2000 \mathrm{~nm}$. Micro hardness studies were carried out using a micro hardness tester, fitted with a diamond indenter using Vicker's hardness method. The elemental analysis was studied using TESCAN SEM-VEGA III and CONTEXT softwares respectively. The NLO property of TTLaB crystal was tested by Kurtz powder SHG (Second Harmonic Generation) test using Nd: YAG laser (1064 nm).

\section{Results and Discussion}

\subsection{Structural Properties}

The obtained crystallographic data from the single crystal XRD analysis revealed that the crystal possess orthorhombic system. The unit cell dimensions were found as $\mathrm{a}=7.130 \AA, \mathrm{b}==9.0907 \AA, \mathrm{c}=10.1131 \AA, \alpha=\beta=$ $\gamma=90^{\circ}$ and the cell volume was $655.49 \AA^{3}$.

\subsection{FTIR Spectral Studies}

Spectroscopic studies were carried out to expound the presence of functional groups. In the FT-IR spectrum Figure 2 of grown crystal of TTLaB, the peaks are observed according to the wave number ranging from 400 $4000 \mathrm{~cm}^{-1}$. The Lanthanum bromide peaks are compared with thiourea (TU) peaks for the corresponding assignment (Table 1). The $\mathrm{NH}$ stretching vibrational bands of $\mathrm{NH}_{2}$ were observed at $3353.84 \mathrm{~cm}^{-1}, 3251.54 \mathrm{~cm}^{-1}$, $3152.54 \mathrm{~cm}^{-1}$ and $2685.12 \mathrm{~cm}^{-1}$ for lanthanum bromide, whereas it was observed at $3380 \mathrm{~cm}^{-1}, 3279 \mathrm{~cm}^{-1}, 3177$ $\mathrm{cm}^{-1}$ and $3190 \mathrm{~cm}^{-1}$ for TU respectively. The IR band for $\mathrm{NH}_{2}$ rocking was observed at $1586.56 \mathrm{~cm}^{-1}$, whereas it was observed at $1620 \mathrm{~cm}^{-1}$ for TU. The N-C-N stretching vibration was found at $1465.51 \mathrm{~cm}^{-1}$ in the observed IR spectrum, whereas it was observed at $1477 \mathrm{~cm}^{-1}$ for TU. The C-S stretching vibration was found at 1414 $\mathrm{cm}^{-1}$ in the observed IR spectrum for TU. The C=S stretching vibration was found at $1430.14 \mathrm{~cm}^{-1}$ in the observed IR spectrum for lanthanum bromide. The IR band for $\mathrm{NH}_{2}$ rocking was observed at $1092.58 \mathrm{~cm}^{-1}$, whereas it was observed at $1082 \mathrm{~cm}^{-1}$ for TU. The symmetric stretching band of C-N was appeared at $730.16 \mathrm{~cm}^{-1}$, whereas it was appeared at $730 \mathrm{~cm}^{-1}$ for TU. The IR band of N-C-S bending vibration was observed at 492.29 $\mathrm{cm}^{-1}$, whereas it was observed at $494 \mathrm{~cm}^{-1}$ for TU. This study (Table 1) reveals that there is a good agreement between thiourea and thiourea present in TTLaB for various FTIR assignments.

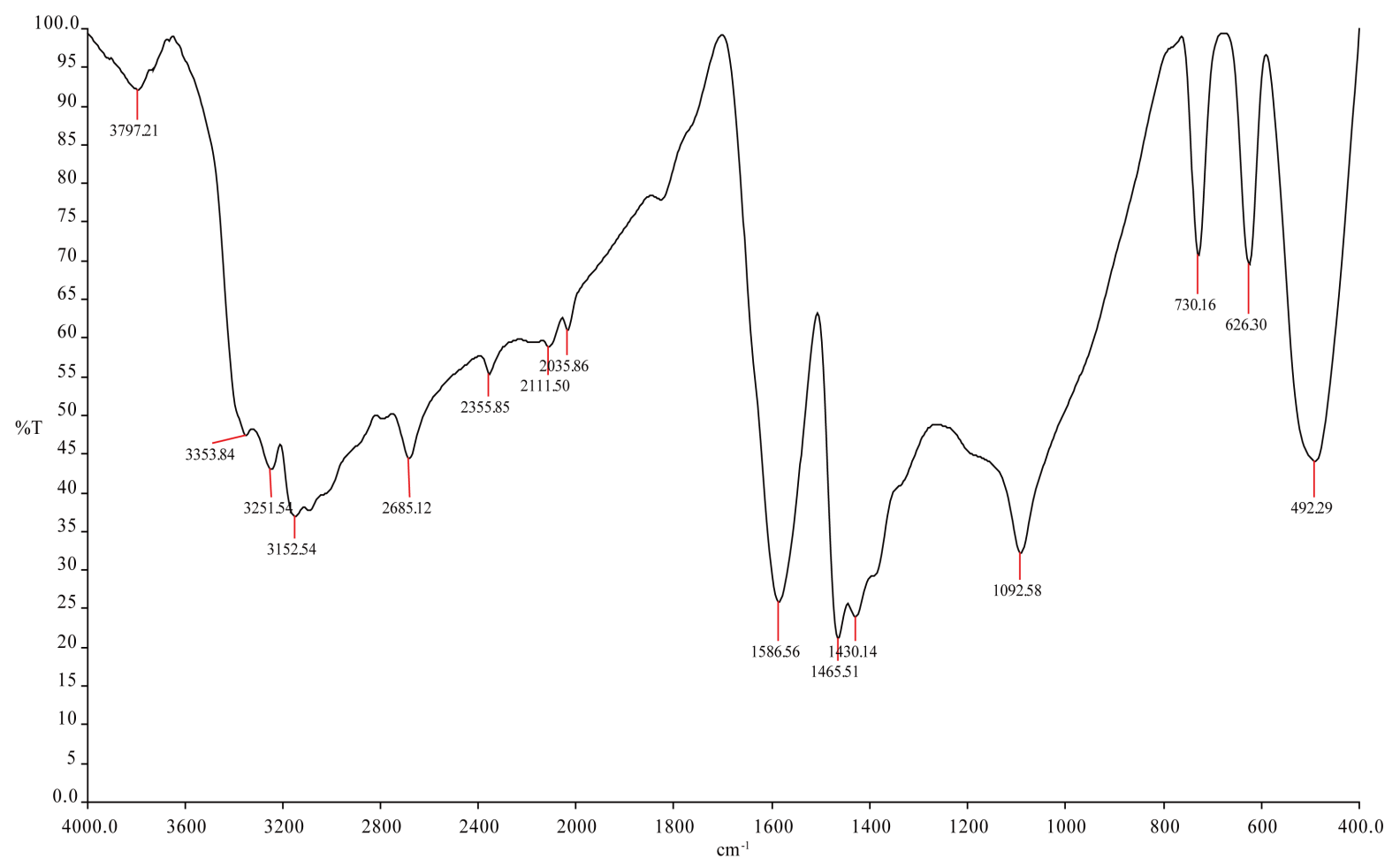

Figure 2. FTIR spectrum of TTLaB. 


\subsection{UV-Vis Analysis}

The recorded transmission spectrum of TTLaB in the range $200-2000 \mathrm{~nm}$ is shown in Figure 3(a). From the optical transmission spectrum, the lower cut off wavelength was observed at $237.43 \mathrm{~nm}$. The crystal has a good transmission in the entire visible region, which gives an advantage in semiorganic nonlinear optical materials. The significant absorbance spectrum is shown in Figure 3(b). Hence, TTLaB crystals can be used for nonlinear optical applications [6].

\subsection{Elemental Analysis}

Energy dispersive X-ray analysis was carried out for characterizing the presence of elements in the title crystal. The recorded energy peaks obtained for different elements were as shown in Figure 4. The presence of $\mathrm{C}, \mathrm{N}, \mathrm{O}$, $\mathrm{La}, \mathrm{S}, \mathrm{Br}$ peaks in EDAX spectrum confirmed the presence of grown TTLaB compound crystal.

\subsection{Mechanical Studies}

To measure the mechanical properties of a solid material, hardness test is imperative, through which the plasticity can be found out. Microhardness testing is the method to find the fracture behaviour, cracking, brittleness of

Table 1. IR vibrational wave numbers and assignments of Thiourea and TTLaB.

\begin{tabular}{ccc}
\hline TU $\mathbf{~ c m}^{-\mathbf{1}}$ & ${\text { TTLaB } \mathbf{~ c m}^{-\mathbf{1}}}$ & Assignment Modes \\
3380 & 3353.84 & $v(\mathrm{~N}-\mathrm{H})$ \\
3279 & 3251.54 & $v(\mathrm{~N}-\mathrm{H})$ \\
3177 & 3152.54 & $v(\mathrm{~N}-\mathrm{H})$ \\
3190 & 2685.12 & $v(\mathrm{~N}-\mathrm{H})$ \\
1620 & 1586.56 & $\delta(\mathrm{N}-\mathrm{H})$ \\
1477 & 1465.51 & $v(\mathrm{~N}-\mathrm{C}-\mathrm{N})$ \\
1414 & 1414 & $v(\mathrm{C}-\mathrm{S})$ \\
---- & 1430.14 & $v(\mathrm{C}=\mathrm{S})$ \\
1082 & 1092.58 & $\rho \mathrm{NH} 2$ \\
730 & 730.16 & $v(\mathrm{C}-\mathrm{N})$ \\
494 & 492.29 & $\delta(\mathrm{N}-\mathrm{C}-\mathrm{S})$ \\
\hline
\end{tabular}

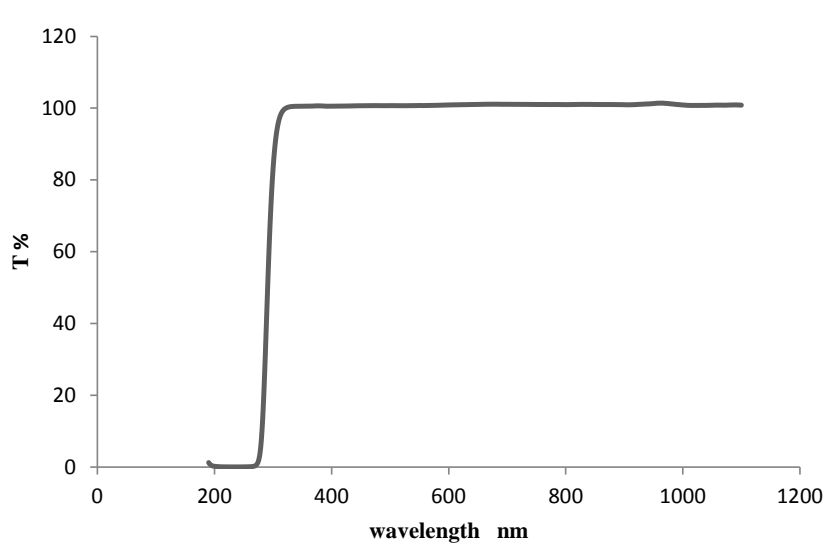

(a)

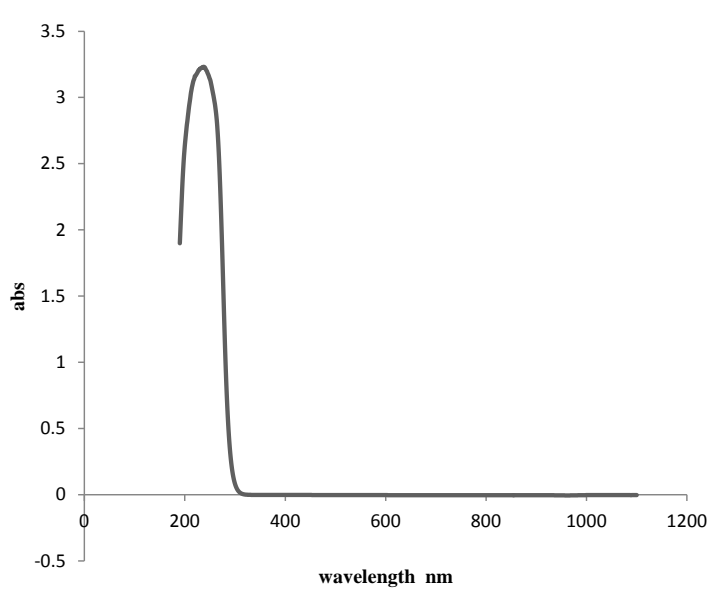

(b)

Figure 3. UV-VIS NIR spectrum of TTLaB. 
a material [7]. The crystal sample was carefully rounded and washed to avoid surface effects. Vicker's microhardness tester was used with diamond indenter. The crystal was placed in the platform of the tester. The Vicker's hardness number $\mathrm{H}_{\mathrm{v}}=1.8544 \mathrm{P} / \mathrm{d}^{2} \mathrm{Kg} / \mathrm{mm}^{2}$, where $\mathrm{P}$ is the applied load in $\mathrm{Kg}$ and $\mathrm{d}$ is the average diagonal length of the indentation mark in mm [8]. Figure 5 shows a graph plotted between $\log \mathrm{P}$ and $\log \mathrm{d}$. The material has a higher hardness property. Figure 6 shows the variation of hardness number with three different loads. The $\mathrm{H}_{\mathrm{v}}$ increases with increase in applied load. The micro hardness study divulges that the grown crystals are mechanically hard. When the hardness values are higher, the stress is also greater which forms dislocations, confirming the crystalline perfection.

\subsection{Second Harmonic Generation}

Active research has been employed to find the NLO property of the title compound. The NLO conversion efficiency was tested using Kurtz and Perry setup [9]. A Q-switched Nd: YAG laser beam (Quanta ray series) supplied by Spectra Physics, USA and Coherent Molectron powermeter, USA, of wavelength $1064 \mathrm{~nm}$ was used with an input power of $0.68 \mathrm{~J}$. The output energy of the sample is $4.1 \mathrm{~mJ}$. The KDP reference energy is $8.8 \mathrm{~mJ}$. Hence, the TTLaB compound crystal has good nonlinearity.

\section{Conclusion}

Single crystals of tristhiourea lanthanum bromide were grown by slow evaporation method. The unit cell parameters for the title crystal have been evaluated by single XRD and the crystal structure is confirmed to be orthorhombic. The comparative study on FTIR spectrum between thiourea and experimental crystals shows the characteristic functional groups. The optical property shows a good transmission and the lower cut off is of $237.43 \mathrm{~nm}$ in the visible range. Elemental analysis confirms the presence of the atoms which belongs to title compound TTLaB. The hardness study confirmed the mechanical strength of the material. SHG analysis corroborates the nonlinearity nature of the crystal. Hence, having good optical property with nonlinearity nature and physical strength TTLaB crystals are useful for NLO device applications.

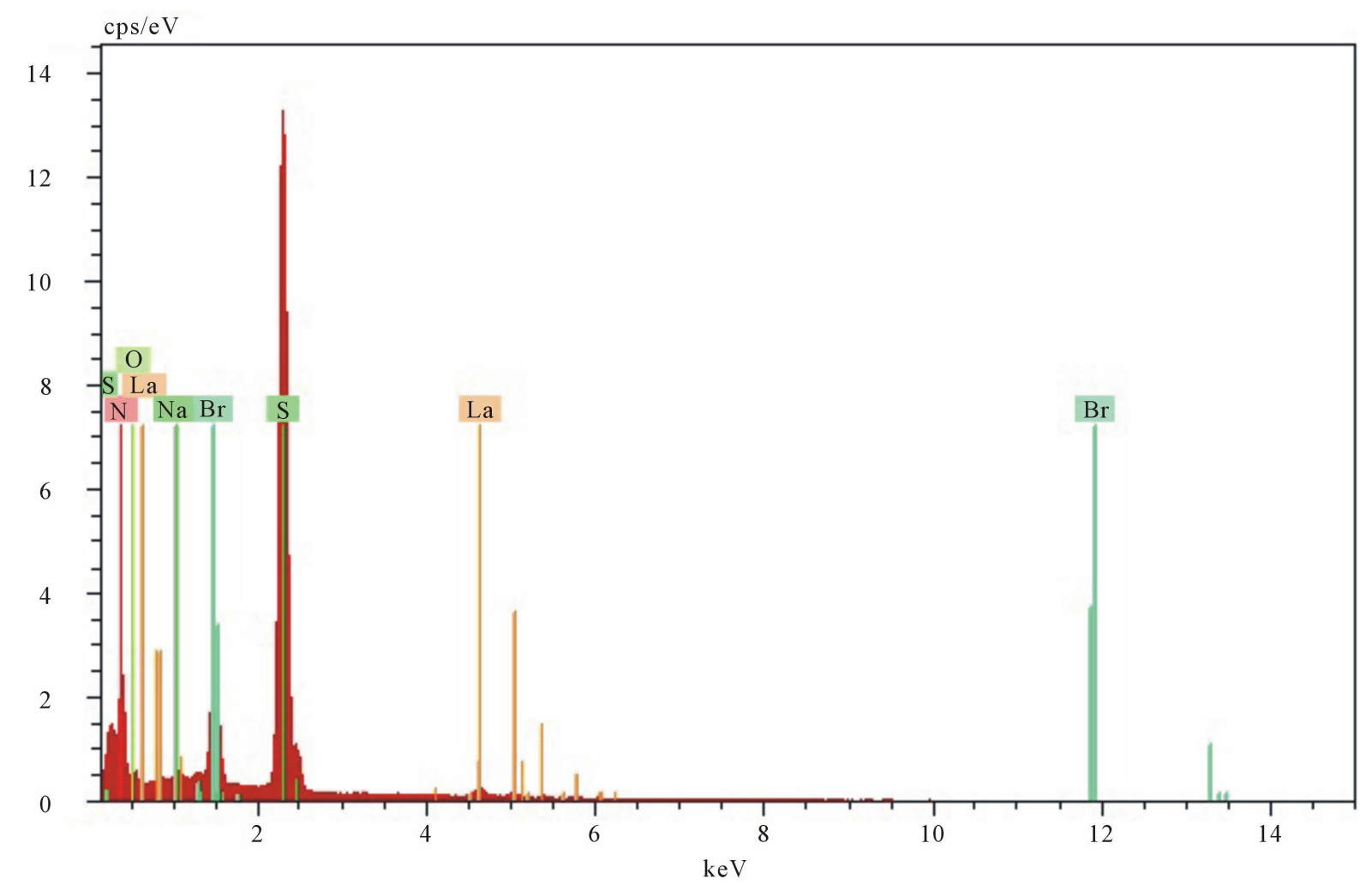

Figure 4. Elemental analysis of TTLaB. 


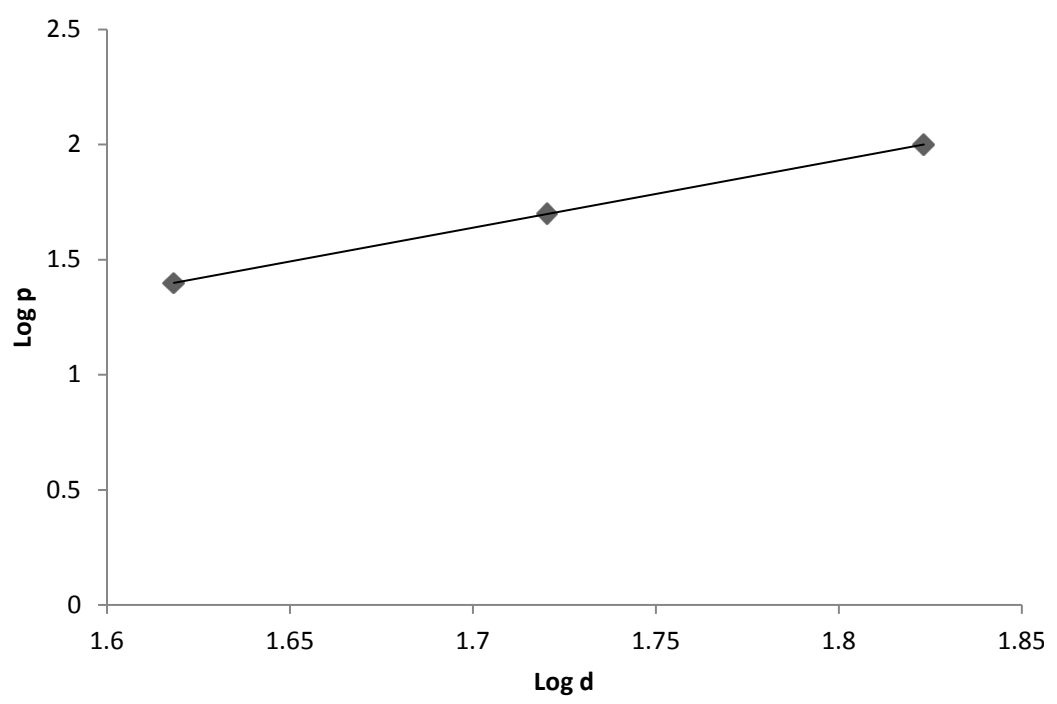

Figure 5. Graph between Log p vs Log d.

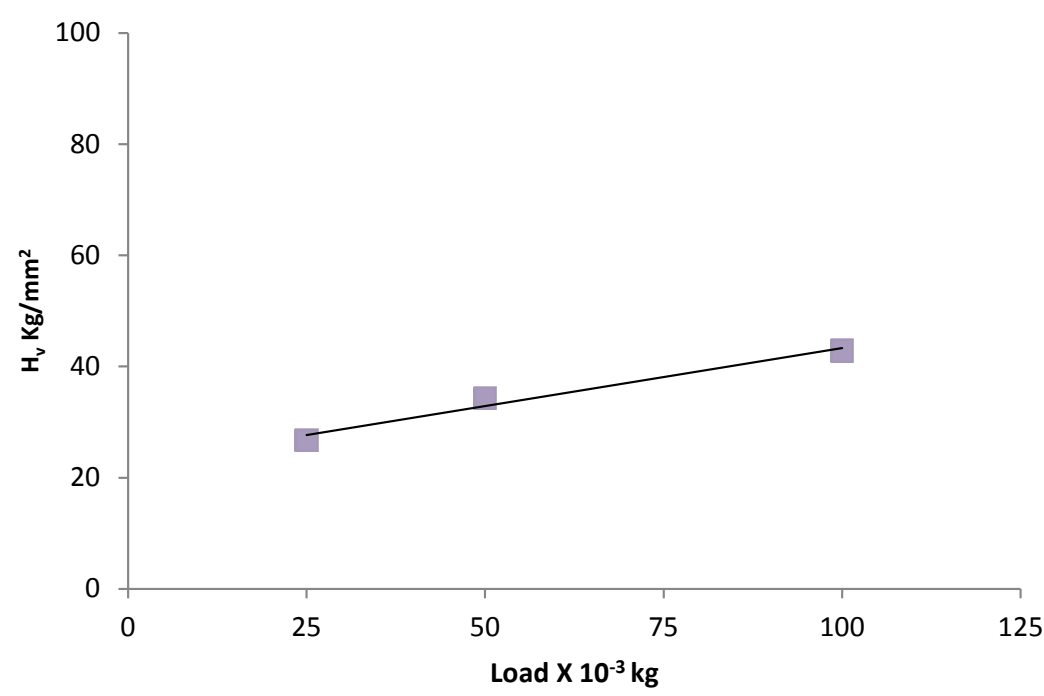

Figure 6. Graph between $\mathrm{H}_{\mathrm{v}}$ vs load.

\section{Acknowledgements}

The authors are thankful for the authorities of St. Joseph's College, Tiruchy, M. K. Univeristy, Madurai, B. S. Abdul Rahuman University, CECRI, Karaikudi for providing instrumental facilities for characterization.

\section{References}

[1] Jiang, M.H., Xu, D., Xing, G.C. and Shao, Z.S. (1985) J. Synth. Cryst., 1, 3-4.

[2] Hou, W.B., Jiang, M.H., Yuan, D.R., Xu, D., Zhang, N., Liu, M.G. and Tao, X.T. (1993) The Preparation and Characterization of a New Organometallic Nonlinear Optical Material-Tri-Allylthiourea Mercury Bromide (ATMB) Crystal, Mater. Materials Research Bulletin, 28, 645-653. http://dx.doi.org/10.1016/0025-5408(93)90108-P

[3] Bhat, S.G. and Dharmaprakash, S.M. (1997) Crystal Growth and Characterization of Antimony Thiourea Bromide. Journal of Crystal Growth, 181, 390-394. http://dx.doi.org/10.1016/S0022-0248(97)00283-2

[4] Prasad, P.N. and Williams, D.J. (1991) Introduction to Nonlinear Optical Effects in Molecules and Polymers. Wiley Interscience, New York.

[5] Angelimary, P.A. and Dhanuskodi, S. (2001) Growth and Characterization of a New Nonlinear Optical Crystal: Bis Thiourea Zinc Chloride. Crystal Research and Technology, 36, 1231-1237. 
http://dx.doi.org/10.1002/1521-4079(200111)36:11<1231::AID-CRAT1231>3.0.CO;2-I

[6] Vijayan, N., Ramesh Babu, R., Gopalakrishnan, R., Ramasamy, P. and Harrison, W.T.A. (2004) Growth and Characterization of Benzimidazole Single Crystals: A Nonlinear Optical Material. Journal of Crystal Growth, 262, 490-498. http://dx.doi.org/10.1016/j.jcrysgro.2003.08.082

[7] Lawn, B. and Wilshaw, R. (1975) Review Indentation Fracture: Principles and Applications. Journal of Materials Science, 10, 1049-1081.

[8] Mott, B.W. (1956) Micro-Indentation Hardness Testing. Butterworths, London, 206.

[9] Kurtz, S.K. and Perry, T.T. (1968) A Powder Technique for the Evaluation of Nonlinear Optical Materials. Journal of Applied Physics, 39, 3798-3813. http://dx.doi.org/10.1063/1.1656857 